\title{
Swimming training promotes cardiac remodeling and alters the expression of mRNA and protein levels involved in calcium handling in hypertensive rats
}

\author{
Jamille Locatelli a,b,*, Leonardo Vinícius Monteiro de Assis ${ }^{c}$, Carolina Morais Araújo a \\ Andréia Carvalho Alzamora a,d,e , Wanderson Geraldo de Lima ${ }^{\mathrm{a}, \mathrm{d}}$, Maria José Campagnole-Santos ${ }^{\mathrm{e}, \mathrm{f}}$, \\ Robson Augusto dos Santos e,f , Mauro César Isoldi ${ }^{\text {a,d }}$
}

a Center for Research in Biological Sciences, Federal University of Ouro Preto, Ouro Preto, Brazil

b Sports Center, Federal University of Ouro Preto, Ouro Preto, Brazil

c Departament of Physiology, Institute of Biosciences, University of São Paulo, São Paulo, Brazil

d Department of Biological Science, Institute of Exact and Biological Sciences, Ouro Preto, Brazil

e National Institute of Science and Technology in Nano-Biopharmaceutical Innovation, Belo Horizonte, Brazil

${ }^{\mathrm{f}}$ Departament of Physiology and Biophysics, Institute of Biological Science, Federal University of Minas Gerais, Belo Horizonte, Brazil

\section{A R T I C L E I N F O}

\section{Article history:}

Received 6 February 2014

Accepted 20 September 2014

Available online 2 October 2014

\section{Keywords:}

Calcium handling

Renovascular hypertension

Swimming

Cardiac hypertrophy

\begin{abstract}
A B S T R A C T
Aim: The aim of this study was to identify the effects of swimming training on the mRNA expression and protein levels of the calcium handling proteins in the hearts of renovascular hypertensive rats submitted to swimming protocol during 6 weeks.

Main methods: Fischer rats with renovascular hypertension 2-kidney 1-clip (2K1C) and SHAM groups were divided among sedentary and exercised groups. The exercise protocol lasted for 6 weeks ( 1 h/day, $5 \times /$ week), and the mean arterial pressure, cardiomyocytes hypertrophy parameters, mRNA expression and protein levels of some calcium handling proteins in the left ventricle were evaluated.

Key findings: Swimming training was able to reduce the levels of mean arterial pressure in the hypertensive group compared to 2K1C SED, and to promote cardiac hypertrophy in SHAM EX and 2K1C EX groups in comparison to the respective control groups. The mRNA levels of B-type natriuretic peptide were reduced in the 2K1C EX when compared to 2K1C SED. The mRNA and protein levels of the sarcoplasmic reticulum $\mathrm{Ca}^{2+}$-ATPase increased after the swimming training in SHAM and 2K1C groups. The mRNA and protein levels of phospholamban, displayed an increase in their levels in the exercised SHAM and in hypertensive rats in comparison to their respective controls; while mRNA levels of $\mathrm{Na}^{+} / \mathrm{Ca}^{2+}$ exchanger was reduced in the left ventricle comparing to the sedentary hypertensive rats.

Significance: Taken altogether, we provide evidence that the aerobic training may lead to cardiac remodeling, and modulate the calcium handling proteins expression in the heart of hypertensive rats.
\end{abstract}

(c) 2014 Elsevier Inc. All rights reserved.

\section{Introduction}

Hypertension is a multifactorial disease that involves interactions between the genetically driven homeostatic control mechanisms and environmental factors (Takahashi and Smithies, 2004). It is estimated that 1 billion people worldwide have hypertension, representing a serious worldwide public health problem mainly because hypertension is a major and well known risk factor for cardiovascular diseases. Several treatment guidelines, pharmacological (Edwards et al., 2014) and

\footnotetext{
* Corresponding author at: Center for Research in Biological Sciences, Federal University of Ouro Preto, Morro do Cruzeiro, Zip Code 35400-000, Ouro Preto, MG, Brazil. Tel.: +55 3135591693.

E-mail address: jahefi@hotmail.com (J. Locatelli).
}

non-pharmacological approaches, such as physical exercise (Semlitsch et al., 2013) have been suggested in order to maintain the blood pressure at acceptable levels.

It is well known that physical exercise is able to reduce the blood pressure levels or even to delay the onset of hypertension in rats with Goldblatt hypertension (Rodrigues et al., 2007; Soares et al., 2011), which is an experimental model dependent on the renin-angiotensin system (RAS) that controls blood pressure in renovascular hypertension. The increase in the activity of this system may lead to hypertension (Reckelhoff et al., 2000), and may also cause deleterious effects on the heart, such as reduction on the $\mathrm{Ca}^{2+}$ transient (Kemi et al., 2007).

The Angiotensin II (Ang II) is an octapeptide produced from the substrate angiotensinogen through sequential enzymatic cleavages by renin and angiotensin converting enzyme (ACE). This peptide is the 
main effector molecule of the RAS, responsible for increased blood pressure by being a potent vasoconstrictor; moreover, Ang II also exerts proliferative, pro-inflammatory, pro-fibrotic activities, and stimulates the production of aldosterone in the adrenal glands (Briet and Schiffrin, 2010; Benigni et al., 2010), which acts on the distal tubules and collecting ducts of the nephron causing sodium retention, potassium secretion, water retention, and blood pressure increase. It is also known that chronic elevation of plasma Ang II is a major determinant in the pathogenesis of cardiac hypertrophy (Egger and Domenighetti, 2010).

The B-type natriuretic peptide (BNP) is a peptide hormone derived from atrial and ventricular cardiomyocytes (Nakatsu et al., 2007). Circulating levels of BNP are normally kept at very low levels; however, in response to increased myocardial wall stress due to volume or pressureoverload states, the production of BNP is triggered in cardiomyocytes (Arjamaa, 2014). Furthermore, BNP is secreted by the ventricle cells in cases of ventricular overload, hypertrophy, and heart failure (Nakatsu et al., 2007; Ogawa et al., 1991; Iso et al., 1997; Kim and Januzzi, 2011). The biological activity of BNP includes: stimulation of natriuresis and vasorelaxation; inhibition of renin, aldosterone and sympathetic nervous activity; inhibition of fibrosis, and improvement in myocardial relaxation (Kim and Januzzi, 2011). Interestingly, the BNP has been shown to be a risk factor for cardiovascular events in hypertensive patients (Suzuki et al., 2002; Weber and Hamm, 2006; Hirata et al., 2001).

The cardiac hypertrophy is classified as eccentric or concentric (Weber et al., 1991). The concentric hypertrophy (pathological) is caused by chronic pressure overload, and leads to reduced left ventricular volume and increased wall thickness; whereas eccentric hypertrophy (in general, physiological) is caused by volume overload, causing dilation and increase in ventricle mass and thickness of the ventricle wall with an increase in cavity diameters (Barry et al., 2008). The eccentric hypertrophy occurs by addition of sarcomeres in series, resulting in cell elongation; on the other hand, the concentric hypertrophy is caused by addition of sarcomeres in parallel, which results in increased cell thickness (Barry et al., 2008).

The pathological cardiac hypertrophy may also lead to changes in the expression of proteins involved in the calcium $\left(\mathrm{Ca}^{2+}\right)$ handling during the cardiac contraction and relaxation (Lu et al., 2002; Collins et al., 2005; Rolim et al., 2007) S Studies have shown reduction on the expression levels of sarcoplasmic reticulum $\mathrm{Ca}^{2+}$-ATPase (SERCA2a) and phospholamban (PLN) (Flesch et al., 1996), and an increase on the expression levels of $\mathrm{Na}^{+} / \mathrm{Ca}^{2+}$ exchanger (NCX1) (Menick et al., 1996) in pathological conditions.

Still, there are controversies regarding the effects of the exercise on the expression of the $\mathrm{Ca}^{2+}$ handling proteins in the heart, which are probably due to the protocols used in the studies. Corroborating this, in spontaneously hypertensive rats (SHR), the voluntary running protocol did not promote any changes on the expression of SERCA2a, and reduced the NCX1 expression levels (Collins et al., 2005). de Waard et al. (2007) showed that the physical exercise when initiated after myocardial infarction did not alter the expression of SERCA2a, PLN, and the phosphorylation status of the latter in mice.

On the other hand, studies using animals with heart failure demonstrated that exercise increased the levels of SERCA2a, and the phosphorylation of PLN on the Ser ${ }^{16}$ residue after 8 weeks of swimming and treadmill training, respectively (Rolim et al., 2007; Medeiros et al., 2008). Furthermore, Wisloff et al. (2001) have also shown increased expression levels of SERCA2a and NCX proteins in mice with infarction after 8 weeks of treadmill protocol.

To the best of our knowledge, there are no studies that investigate the effects of swimming training during 6 weeks in the prevention of the cardiac remodeling, and its relation with the calcium handling proteins in renovascular hypertensive rats. Based on this, our goal here was to identify the effects of swimming training on the mRNA expression and protein levels of the calcium handling proteins in the hearts of renovascular hypertensive rats submitted to a swimming protocol during 6 weeks.

\section{Materials and methods}

\section{Animal care and ethical approval}

Thirty-seven Fischer rats were maintained in a light (12-h light cycle) and in temperature $\left(22^{\circ} \mathrm{C}\right)$ controlled environment, and were fed a pellet rodent diet ad libitum with free access to water. The animals were randomly assigned into untrained and exercise-trained groups. This study was conducted in accordance with the ethical principles in animal research adopted by the EU Directive 2010/63/EU for animal experiments. The animal care and protocols in this study were reviewed and approved by the Ethical Committee of the University of Ouro Preto (protocol number 2010/45).

\section{Measurements and procedures}

\section{Hypertension model}

The 2K1C unilateral renovascular hypertension model (Goldblatt hypertension) was performed by constricting the left renal artery. Briefly, the animals were anesthetized by intraperitoneal injection with a mixture of ketamine and xylazine (50 and $10 \mathrm{mg} / \mathrm{kg}$, ip, respectively, Syntec, Brasil). After the laparotomy, the left renal artery was isolated and was partially constricted using a 3-mm-long, wide U-shaped silver clip with an internal gap of $0.20 \mathrm{~mm}$. The rats that were assigned as control groups had the surgical intervention performed, but the left renal artery was left unclipped. The experiments started after the fourth day of the recovery period.

\section{Swimming training protocol}

The exercise protocol was performed in a swimming apparatus especially designed for the exercise training of rats, in which the rats swam individually and freely without human intervention in warm water $\left(30-32^{\circ} \mathrm{C}\right)$ for 5 days a week during 6 weeks, and each session lasted for $60 \mathrm{~min}$. All untrained rats were placed in recipients with shallow water $(5 \mathrm{~cm})$ for 5 days a week during 6 weeks, and each session lasted for $40 \mathrm{~min}$ (Soares et al., 2011). The animals were submitted to the swimming training without an overload because it is known that this model induces physiologic cardiac hypertrophy (Evangelista et al., 2003).

\section{Arterial pressure measurements}

At the end of the sixth week, $48 \mathrm{~h}$ after the conclusion of the EX protocol, the rats were anesthetized with a mixture of ketamine and xylazine (50 and $10 \mathrm{mg} / \mathrm{kg}$, ip, respectively, Syntec, Brasil) for direct cardiovascular evaluation, and the femoral artery was cannulated. Twenty-four hours after the surgery, the pulsatile arterial pressure was monitored with a Gould pressure transducer (PM-1000, CWE, USA) coupled to a blood pressure signal amplifier (UIM100A, Powerlab System, AD Instruments, USA). The values of mean arterial pressure (MAP) were determined by the arterial pressure waves. All variables were recorded and stored in a PowerLab digital acquisition system (Powerlab 4/20, AD Instruments) with an 800-Hz sampling rate.

\section{Tissue and organ collection}

After the conclusion of the experiments, the animals were euthanized by decapitation, and had a laparotomy performed for the resection of the heart, which was weighted (wet weight). The hearts, kidneys and tibia were stored at $-80^{\circ} \mathrm{C}$ along for future analysis.

\section{Structural analysis}

The left ventricle was fixed by immersion in $4 \%$ buffered formalin and embedded in paraffin for routine histology processing. Sections of $4 \mu \mathrm{m}$ were stained with hematoxylin and eosin to further examination under a microscope. All the morphometric measurements were made in tissue sections under the light of the microscope (Leica DM5000), 
and analyzed with the Leica Qwin Image Processing and Analysis Software (Germany). The cardiomyocyte diameter was measured by the method described by Loud et al. (1978) in a light microscope at $40 \times$ magnification. For every 10 cardiomyocytes containing a visible nucleus in the field a single transverse measurement of width passing through the nucleus was determined. The diameter was determined for each animal by the average of the measured cardiomyocytes. Morphometric analysis was used to quantify the tissue collagen deposition as described by Soares et al. (2011). The degree of cardiac hypertrophy was calculated as the ratio between the left ventricle wall thickness $(\mathrm{Wt})$, and the left ventricle lumen $(\mathrm{L})(\mathrm{Wt} / \mathrm{L})$. The left ventricle wall thickness and ventricle lumen were determined on sections at $5 \times$ magnification (Soares et al., 2011).

\section{Real time-PCR}

Total RNA was isolated from the left ventricles of the control and $2 \mathrm{~K} 1 \mathrm{C}$ rats with a Trizol reagent (Invitrogen Life Technologies, Carlsbad, CA, USA) according to the manufacturer's protocol. Samples of RNA $(2 \mu \mathrm{g})$ were treated with DNase to remove any genomic DNA present in the samples. The gene expression was assessed by polymerase chain reaction after real time-PCR. The total RNA treated with DNase was reverse transcribed using random primers. The RT-PCR was performed with QuantiTect SYBR Green RT-PCR kit (Qiagen) with a pair of primers for SERCA2, FLB and NCX (Qiagen). The sequences of the forward ( $\mathrm{f}$ ) and the reverse ( $\mathrm{r}$ ) primers are provided in Table 1. The 26S was adopted as an internal standard and mRNA levels were expressed relative to male $2 \mathrm{~K} 1 \mathrm{C}$. The amplification and quantification were performed using the iCycler iQ Real-Time detection system under the following conditions: RT-PCR activation step $15 \mathrm{~min}$ at $95{ }^{\circ} \mathrm{C}$; denaturation for $15 \mathrm{~s}$ at $94{ }^{\circ} \mathrm{C}$, annealing for $30 \mathrm{~s}$ at $55^{\circ} \mathrm{C}$; and extension for $30 \mathrm{~s}$ at $72{ }^{\circ} \mathrm{C}$ for 40 cycles (Applied Biosystems). Each sample was performed in duplicate and the mean threshold cycle $\left(C_{t}\right)$ was used to calculate the relative mRNA expression (fold change) using the comparative $C_{t}$ method $\left(2^{-\Delta \Delta C t}\right)$.

\section{Western blot analysis}

For Western blot analysis total protein was harvested from the heart tissue. After lysis with $300 \mu$ of PhosphoSafe extraction buffer containing protease inhibitors (Roche), the protein concentration was determined with the BCA protein assay kit (Pierce). The mixture of loading gel, antioxidant agent (Invitrogen) and $25 \mu$ of protein was heat denatured $\left(70{ }^{\circ} \mathrm{C}\right.$ for $10 \mathrm{~min}$ ), and loaded into a $10 \%$ NuPAGE Tris-Bis gel (Invitrogen). Electrophoresis was performed at $200 \mathrm{~V}$ and $100 \mathrm{~mA}$ for $50 \mathrm{~min}$. After transfer ( $30 \mathrm{~V}$ and $170 \mathrm{~mA}$ ) to PDVF membranes, the blot was developed by using the WesternBreeze chromogenic immunodetection kit (Invitrogen). Briefly, nonspecific sites were blocked $(1 \mathrm{~h})$, and the membranes were incubated overnight at $4{ }^{\circ} \mathrm{C}$ with: SERCA2 (rabbit polyclonal to SERCA2 ATPase, ABCAM, catalog ab3625) and phospholamban (rabbit polyclonal to phospholamban, ABCAM, catalog ab86930) antibodies. $\beta$-Actin was used as loading

Table 1

Primer sets for real-time quantitative RT-PCR.

\begin{tabular}{lll}
\hline Gene & & Sequence $\left(5^{\prime} \rightarrow 3^{\prime}\right)$ \\
\hline SERCA2 & f & TCTGTCATTCGGGAGTGGGG \\
NCX1 & r & GCCCACACAGCCAACGAAAG \\
& f & GTGGAGGTCTGGGAAGAATT \\
Phospholamban & r & GCTTCCTCGTCATCTTGGTC \\
BNP & f & TGTGACGATCACAGAAGCC \\
& r & GCAGCAGACATATCAAGATGAG \\
$26 S$ & f & AGAACAATCCACGATGCAG \\
& r & CCTTGGTCCTTGAGAGCTG \\
& f & CGATTCCTGACAACCTTGCTATG \\
\hline
\end{tabular}

control antibody (1:1000 dilution; Cell Signaling Biotechnology, \#4967). Membranes were then rinsed (four times, $5 \mathrm{~min}$ ) with the kit antibody washing solution, incubated in the alkaline phosphataseconjugated anti-rabbit secondary antibody for $1 \mathrm{~h}$ at room temperature, rinsed again (four times, $5 \mathrm{~min}$ ), and finally placed in a solution of 5 bromo-4-chloro-3-indolyl-1- phosphate and nitro blue tetrazolium (BCIPNBT) substrate for alkaline phosphatase until bands appeared. After rinsing in water, the membranes were air-dried, scanned, digitalized, and the optical densities were quantified by using NIH IMAGE software (Version 1.62, by Wayne Rasband, National Institutes of Health, Bethesda). Band densities were normalized to that of the anti $\beta$-actin immunoreactive band within the same lane.

\section{Statistical analysis}

The means and the standard deviations of the values were compared among the groups by the analysis of the variance (one-away ANOVA), followed by the Tukey test for blood pressure, hypertrophy, mRNA, and Western blot data. Nonparametric statistic was used to analyze collagen deposition and left ventricular cross-sectional (Kruskal-Wallis test). These analyses were performed by GraphPad Prism 5. The differences were considered significant at $\mathrm{P}<0.05$.

\section{Results}

Basal levels of mean arterial pressure (MAP)

The basal levels of MAP in SHAM and 2K1C rats in waking state are shown in Fig. 1. We observed that resting levels of MAP in the $2 \mathrm{~K} 1 \mathrm{C}$ SED rats were higher than in the SHAM SED and SHAM EX rats. The resting levels of MAP in 2K1C EX rats were smaller when compared to the 2K1C SED rats (Fig. 1).

\section{Histological heart evaluation}

We observed in Fig. 2 that SHAM EX animals had significantly higher values of cell thickness compared to the SHAM SED. On the other hand, the 2K1C EX group showed significant increase in cell thickness compared to other groups (SHAM SED, SHAM EX and 2K1C SED). The analysis of collagen deposition showed no difference between the groups (Fig. 3). In Fig. 4, there is a representation of photomicrographs of the left ventricle of SHAM and 2K1C groups.

As shown in Table 2, the Wt/L ratio was higher in 2K1C SED and 2K1C EX animals compared to SHAM SED rats, which suggests a concentric hypertrophy profile. This ratio was lower in SHAM EX rats compared to SHAM SED rats, suggesting an eccentric hypertrophy profile. No

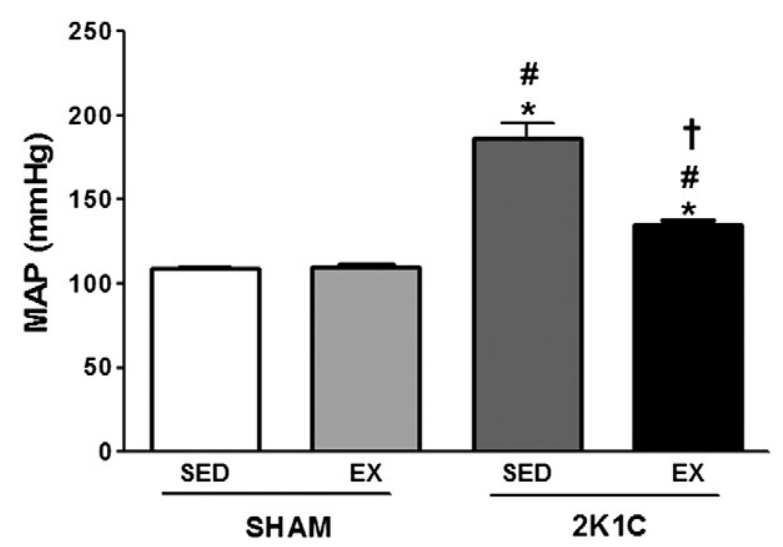

Fig. 1. The mean arterial pressure $(\mathrm{mm} \mathrm{Hg})$ in sedentary rats and exercised rats. Data are shown as mean $\pm \mathrm{SD}$. ${ }^{*} \mathrm{P}<0.005$ compared to SHAM SED rats. ${ }^{*} \mathrm{P}<0.005$ compared to the SHAM EX rats. ${ }^{\dagger} \mathrm{P}<0.005$ vs. 2 K1C SED rats (one way ANOVA followed by the Tukey test). SHAM SED, $\mathrm{n}=10$; SHAM EX, $\mathrm{n}=9$; 2K1C SED, $\mathrm{n}=9$; 2K1C EX, $\mathrm{n}=9$. 


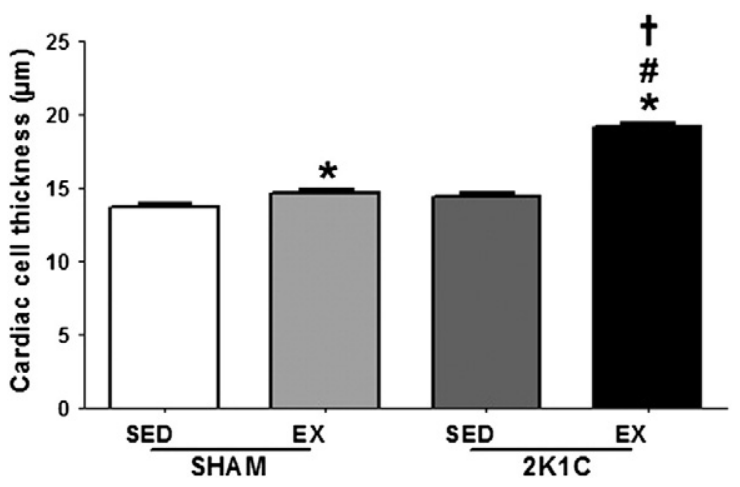

Fig. 2. The cardiac fibers thickness ( $\mu \mathrm{m})$ in the SHAM and $2 \mathrm{k} 1 \mathrm{C}$ groups. ${ }^{*} \mathrm{P}<0.05$ compared to SHAM SED. ${ }^{*} \mathrm{P}<0.005$ compared to SHAM EX. ${ }^{\dagger} \mathrm{P}<0.005$ compared to $2 \mathrm{~K} 1 \mathrm{C}$ SED (oneway ANOVA followed by the Turkey test). SHAM SED, $n=10$; SHAM EX, $n=9$; 2K1C SED, $\mathrm{n}=9 ; 2 \mathrm{~K} 1 \mathrm{C}$ EX, $\mathrm{n}=9$.

difference was observed in the left ventricle $\mathrm{Wt} / \mathrm{L}$ ratio between 2K1C groups; although we have observed a decreasing tendency on the $\mathrm{Wt} / \mathrm{L}$ ratio. Likely this was due to the small number of animals used, and the length of the exercise protocol used in our work. Fig. 5 shows the left ventricular cross-sectional of the SHAM and $2 \mathrm{~K} 1 \mathrm{C}$ rats.

\section{Cardiac BNP expression evaluation}

In Fig. 6, we observed that in 2K1C SED and 2K1C EX animals there was an increase in the expression of BNP in comparison to the SHAM SED animals. The 2K1C EX animals showed a reduction in the expression of this marker compared to the 2K1C SED animals.

The expression levels of the calcium handling proteins in the cardiac tissue

In order to verify whether the physical exercise influence the improvement of the calcium handling, we evaluated the mRNA expression and protein levels of some key proteins of this process.

\section{SERCA2 a mRNA and protein levels}

In Fig. 7, we observed that the mRNA levels of SERCA2a increased in the SHAM EX (410\%) compared to the SHAM SED. The 2K1C EX animals had an increase in the expression on the levels of SERCA2a in comparison to the SHAM SED (350\%) and 2K1C SED animals (291\%). Fig. 8 shows a Western blot analysis of SERCA2a protein expression, which indicates an increase in protein levels in $2 \mathrm{~K} 1 \mathrm{C}$ group subject to training in comparison to sedentary hypertensive group.

\section{Phospholamban mRNA and protein levels}

In Fig. 9, we observed that physical exercise was able to increase the expression levels of phospholamban in SHAM EX group when compared to SHAM SED (2023\%); however, in 2K1C EX group we

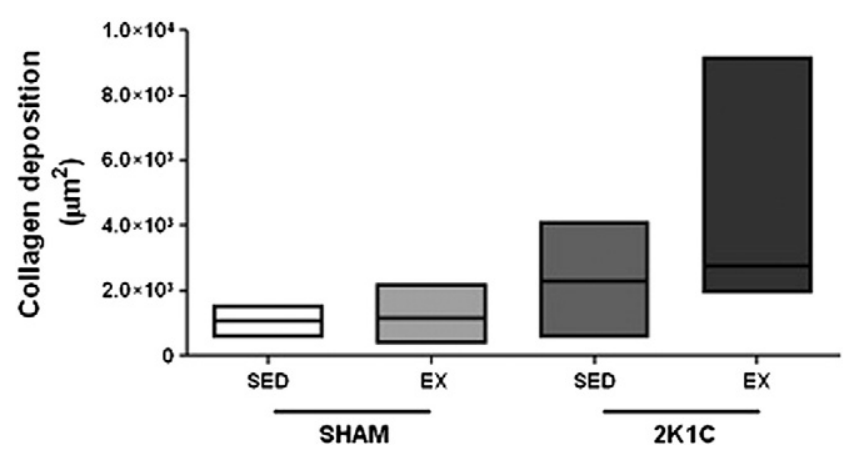

Fig. 3. Left ventricule collagen deposition in sedentary rats and exercised tats. No differences were observed (Kruskal-Wallis test).

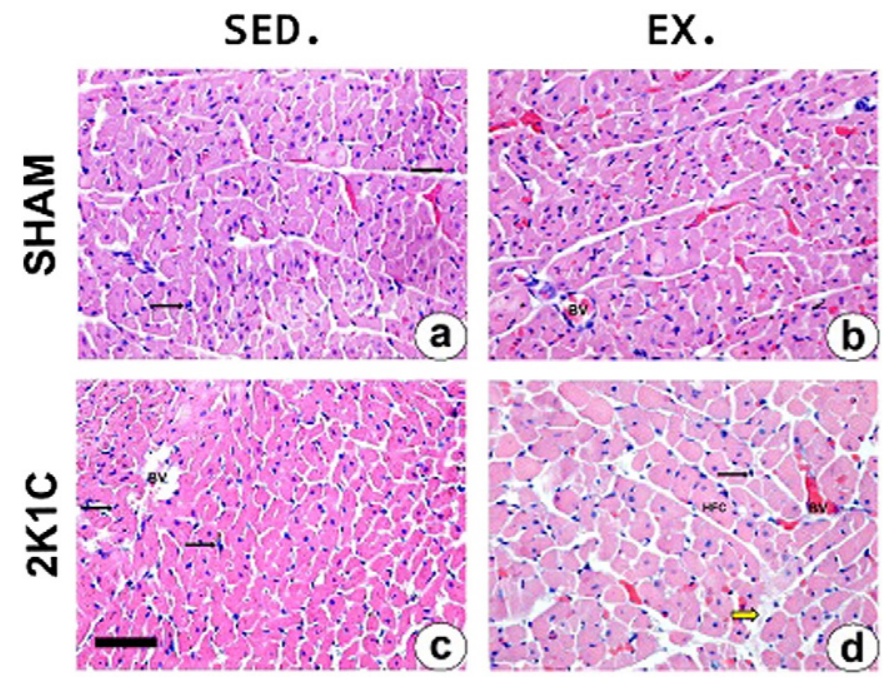

Fig. 4. Left ventricle photomicrography of the SHAM and $2 \mathrm{~K} 1 \mathrm{C}$ rats showing cardiomyocytes. Hematoxylin and eosin. Bar $=75$ micromeres $(\mathrm{pm})$. Black arrows indicate inflammatory ${ }^{7}$ cell; Yellow arrow indicate fibrotic areas. BV: Blood vessel; HFC: Hypertrophic cardiomyocyte.

observed an increase on the expression levels of phospholamban in comparison to the SHAM and 2K1C (2000\%) sedentary groups. Fig. 10 shows a Western blot of PLN protein levels, where we found the same increase observed for the SERCA protein regarding the training animals.

\section{NCX1 mRNA}

The NCX1 levels increased in the 2K1C SED group compared to the SHAM SED and EX groups (473\%). The physical exercise was able to reduce the levels of mRNA in the 2K1C EX compared to the $2 \mathrm{~K} 1 \mathrm{C}$ SED in approximately $1150 \%$ (Fig. 11). We did not detect any NCX1 band in the Western blot assay.

\section{Discussion}

The cardiac hypertrophy is related to significant alterations in the myocardial contractility; however, the role of exercise training in the modulation on the expression levels of the proteins involved in the calcium handling in cardiomyocytes of rats, which is due to the diversity of the protocols used in the literature, is not yet established.

It has been reported that exercise training reduces the levels of blood pressure in patients with hypertension (Kohlmann et al., 1999; Padmalayam, 2012), and this decrease is intensity dependent (Molmen-Hansen et al., 2012). There are few studies that correlate the effects of the aerobic exercise in rats with renovascular hypertension. For example, Rodrigues et al. (2007) and Soares et al. (2011) have shown that the swimming training was able to reduce the levels of blood pressure in renovascular hypertensive rats. Still, the literature is still inconclusive regarding the mechanisms that trigger this response during 6 weeks of the $2 \mathrm{~K} 1 \mathrm{C}$ renovascular hypertension model.

The reduction of blood pressure levels after the exercise is related to a decrease in the activity of RAS associated with a reduction on plasma levels of rennin (Molmen-Hansen et al., 2012), Ang II, aldosterone, and vasopressin (Duncan et al., 1985). It is likely that the decrease in the

Table 2

Left ventricle wall thickness/lumen ratio (Wt/L) of SHAM and 2K1C rats.

\begin{tabular}{lllll}
\hline Groups & $\begin{array}{l}\text { SHAM SED } \\
(\mathrm{n}=5)\end{array}$ & $\begin{array}{l}\text { SHAM EX } \\
(\mathrm{n}=5)\end{array}$ & $\begin{array}{l}\text { 2K1C SED } \\
(\mathrm{n}=3)\end{array}$ & $\begin{array}{l}\text { 2K1C EX } \\
(\mathrm{n}=3)\end{array}$ \\
\hline Mean & 0.6724 & $0.4619^{*}$ & $0.8357^{*}$ & $0.7496^{*}$ \\
SD & \pm 0.00382 & \pm 0.226 & \pm 0.02409 & \pm 0.00061 \\
\hline$* \quad \mathrm{P}<0.05$ compared to SHAM SED & & &
\end{tabular}


SHAM
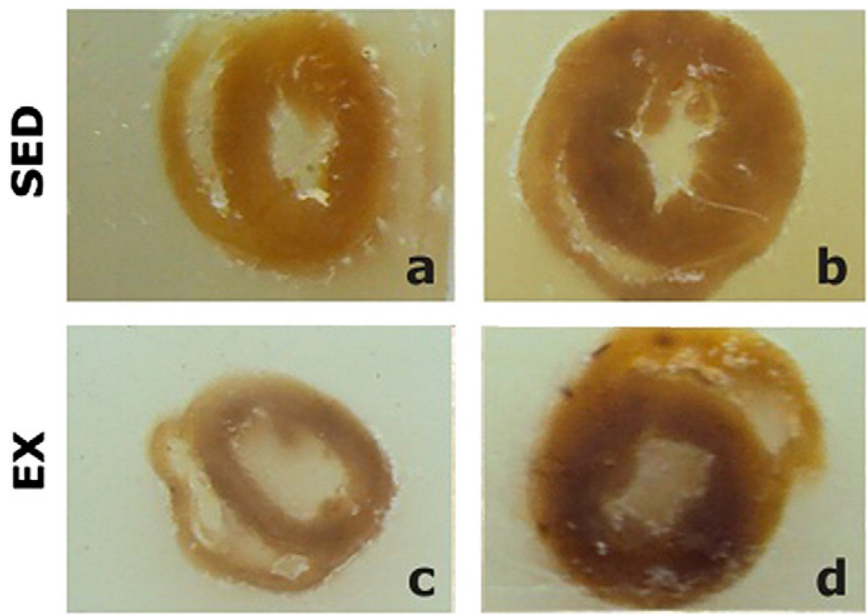

C
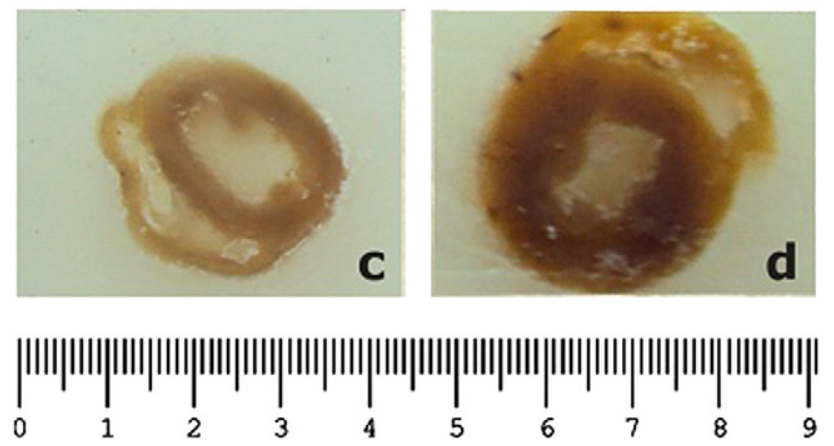

Fig. 5. Left ventricular cross-sectional of the SHAMand 2K1C rats.

blood pressure found in our study is multifactorial (Fig. 1); however to an extent, the reduction found on blood pressure is related to RAS suffering the influence of the peripheral oxidative metabolism.

The concentric hypertrophy is characterized by an increase in ventricular mass with proliferation of fibroblast (Wakatsuki et al., 2004), which leads to reduction in cavity diameters. Our data show a pattern of concentric hypertrophy both in sedentary and exercised hypertensive rats; however, we did not find any difference in the collagen content between the groups (Fig. 3).

The collagen is a structural protein responsible for the functional integrity of the myocardium, allowing the interdigitation and force transmission between the myocytes in contraction process (Weber et al., 1987); however, loss or damage in collagen network in the heart could compromise the systolic function (Janicki and Brower, 2002). According to Weber et al. (1987), in a pressure overload scenario, the collagen is proportional in comparison to the hypertrophic muscle seems to be higher; however, in our work we have not observed any significant difference in the collagen content between the groups (Fig. 3). On the other hand, other studies have demonstrated the efficacy of

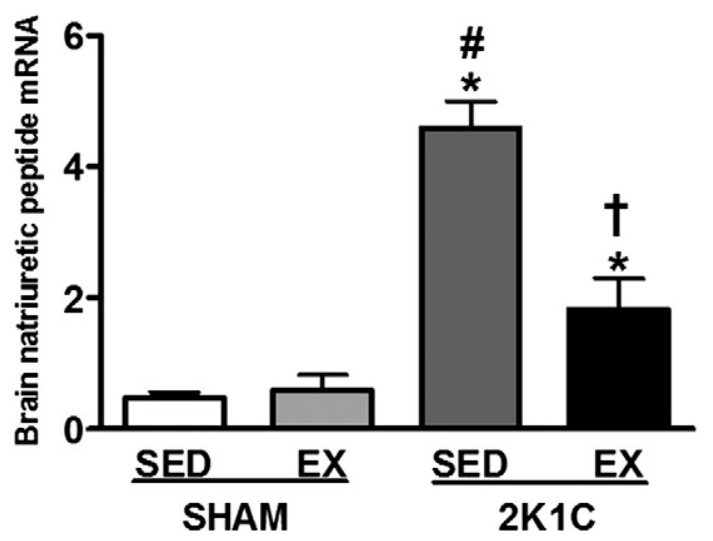

Fig. 6. Cardiac mRNA expression levels of Brain Natriuretic Peptide in sedentary rats and exercised rats. mRNA levels of BNP as ratio to $26 \mathrm{~S}$ mRNA levels. ${ }^{*} \mathrm{P}<0.05$ compared to SHAM SED. ${ }^{\#} \mathrm{P}<0.005$ compared to SHAM EX. ${ }^{\dagger} \mathrm{P}<0.005$ compared to $2 \mathrm{~K} 1 \mathrm{C}$ SED (ANOVA followed by the Tukey test). SHAM SED, $\mathrm{n}=10$; SHAM EX, $\mathrm{n}=9$; 2 K1C SED, $\mathrm{n}=9 ; 2 \mathrm{~K} 1 \mathrm{C}$ EX, $\mathrm{n}=9$.

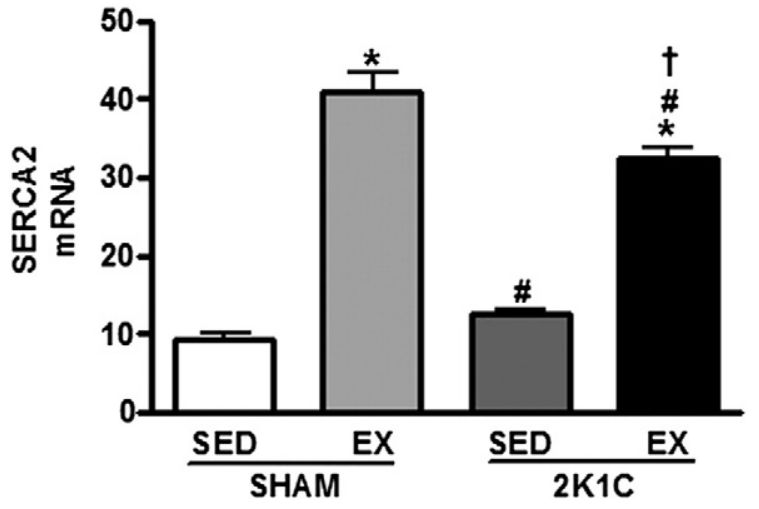

Fig. 7. SERCA2a mRNA expression levels in sedentary rats and rats subjected to exercise training. ${ }^{*} \mathrm{P}<0.001$ compared to SHAM SED. ${ }^{\#} \mathrm{P}<0.001$ compared to SHAM EX. ${ }^{\dagger} \mathrm{P}<0.001$ compared to 2K1C SED (one-way ANOVA followed by the Tukey test). SHAM SED, $\mathrm{n}=10$; SHAM EX, $\mathrm{n}=9$; 2 K1C SED, $\mathrm{n}=9$; 2 K1C EX, $\mathrm{n}=9$.

the exercise in reducing the collagen content in hearts of rats submitted to exercise (Kwak et al., 2006; Thomas et al., 2001; Kwak et al., 2011). Therefore, it is likely that this result was due because of the length of the exercise protocol used in our work, and it is further explained below.

Even though we have not observed an increase in the collagen content, and in cardiac cell thickness in the 2K1C SED, we have observed a significant difference in the levels of BNP, and on Wt/L ratio (Figs. 2-4). This data indicate that the hypertensive group suffered the deleterious effect of RAS promoted by hypertension. Likewise, the 2K1C EX displayed an increase on Wt/L ratio in comparison to SHAM SED. The increase in the cardiac fiber thickness found in 2K1C EX group when compared to SHAM and 2K1C SED indicates that RAS has also promoted deleterious effects, even in the absence of significant differences in the collagen content. Therefore, our data show that the duration of our protocol was not sufficient to fully reverse the pathological hypertrophy present in the hypertensive group, but it was able to reduce the levels of BNP, which shows some beneficial effects of our exercise protocol in the hypertensive heart.

Corroborating and strengthening our findings, our laboratory has shown significant alterations in the hypertrophy patterns in hypertensive animals after swimming training during 5 weeks without an
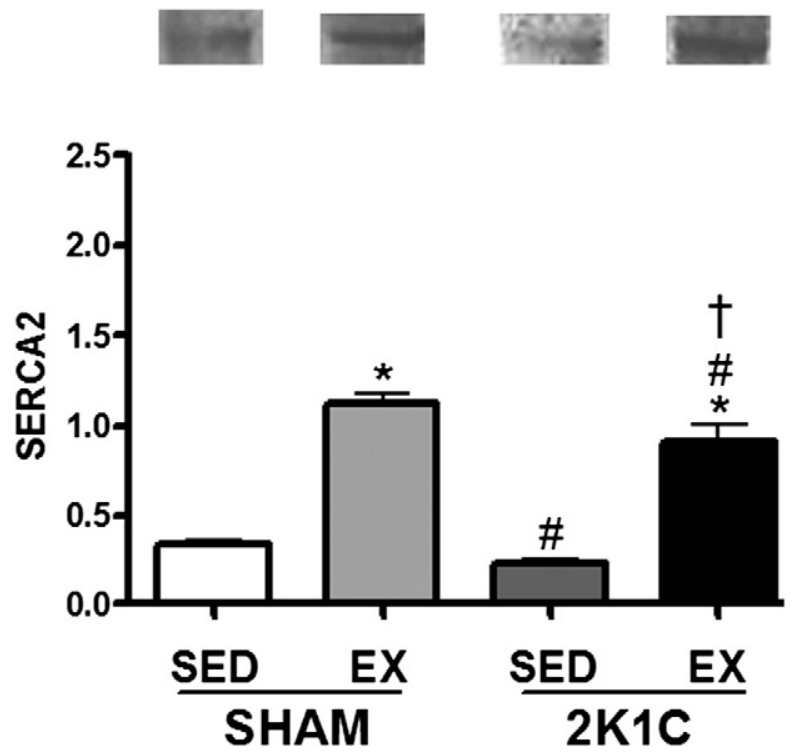

Fig. 8. SERCA protein expression levels in sedentary rats and rats subjected to exercise training. ${ }^{*} \mathrm{P}<0.05$ compared to SHAMSED. ${ }^{*} \mathrm{P}<0.05$ compared to SHAM EX. ${ }^{\dagger} \mathrm{P}<0.01 \mathrm{com}-$ pared to 2K1C SED (one-way ANOVA followed by the Tukey test). SHAM SED, $n=6$; SHAMEX, $\mathrm{n}=6$; 2 K1C SED, $\mathrm{n}=6$; $2 \mathrm{~K} 1 \mathrm{C}$ EX, $\mathrm{n}=6$. 


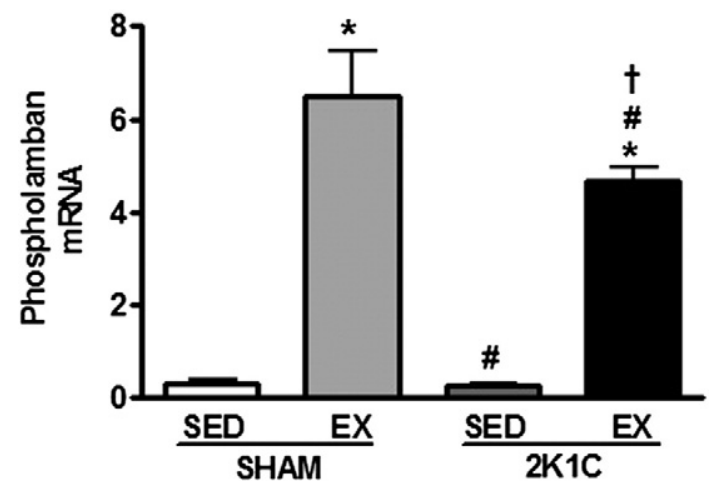

Fig. 9. Phospholamban mRNA expression levels in sedentary rats and rats subjected to exercise training. ${ }^{*} \mathrm{P}<0.001$ compared to SHAM SED. ${ }^{\#} \mathrm{P}<0.001$ compared to SHAM EX. ${ }^{\dagger} \mathrm{P}<0.001$ compared to 2K1C SED (one-way ANOVA followed by the Tukey test). SHAM SED, $n=10$; SHAM EX, $n=9$; 2K1C SED, $n=9 ; 2 K 1$ C EX, $n=9$.

overload (Soares et al., 2011). Unpublished data from our laboratory have shown that swimming training during 8 weeks without an overload also promotes ventricle remodeling in rats with renovascular hypertension. In this same study, it was observed that the duration of 4 weeks did not alter the Wt/L ratio in hypertensive rats. Given this, it seems the duration of our protocol is working in a transitional phase of the cardiac remodeling in the hearts of rats with renovascular hypertension, and may accentuate this response in later stages, in which we observe physiological hypertrophy (unpublished data).

In eccentric hypertrophy there is an increase in the mass of the ventricle and in the thickness of ventricle wall with an increase in the cavity diameters (Wakatsuki et al., 2004), which was observed in the animals SHAM EX. The exercise protocol used in this study was able to promote a physiological cardiac hypertrophy; even though it was not enough to fully reverse the pathological hypertrophy found in the hypertensive animals (Figs. 2, 4, and 5; Table 2). Our physical exercise protocol started 4 days after the implantation of the silver clip in the renal artery. Thus looking at the results of the cardiac fiber thickness, we can infer that the cardiac remodeling seems to be associated with the swimming training, since only a significant difference in the cell thickness in animals subjected to the exercise training was seen (Fig. 2).
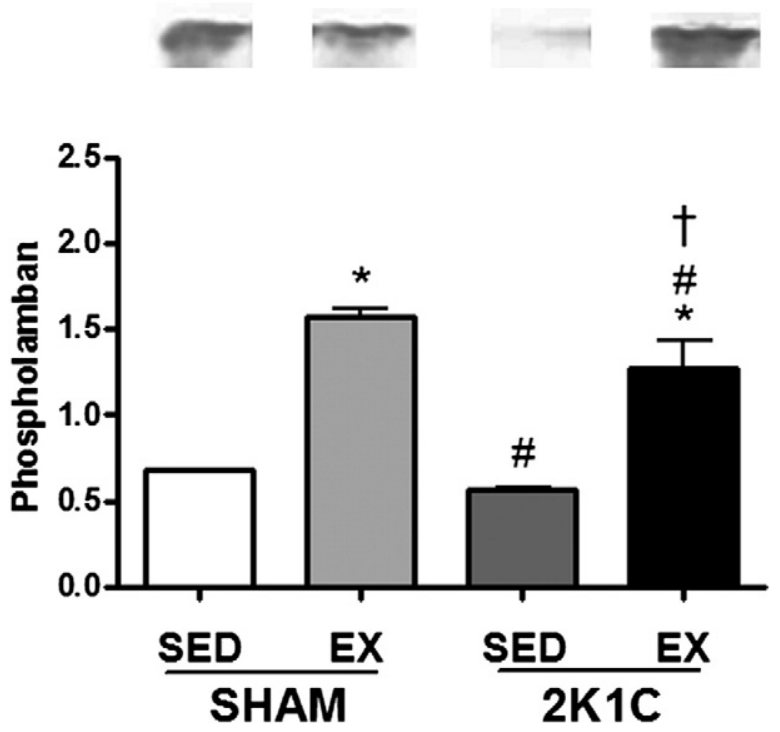

Fig. 10. Phospholamban protein expression levels in sedentary rats and rats subjected to exercise training. ${ }^{*} \mathrm{P}<0.001$ compared to SHAM SED. ${ }^{*} \mathrm{P}<0.001$ compared to SHAM EX. ${ }^{\dagger} \mathrm{P}<0.001$ compared to 2K1C SED (one-way ANDVA followed by the Tukey test). SHAM SED, $n=6$; SHAM EX, $n=6 ; 2$ K1C SED, $n=6 ; 2 K 1 C$ EX, $n=6$.

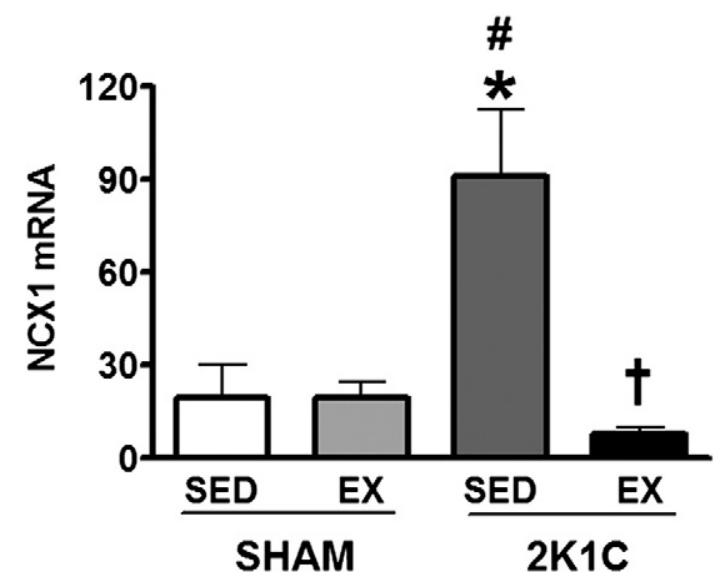

Fig. 11. NCX1 mRNA expression levels in sedentary rats and rats subjected to exercise training. ${ }^{*} \mathrm{P}<0.05$ compared to SHAM SED. ${ }^{\#} \mathrm{P}<0.05$ compared to SHAM EX. ${ }^{\dagger} \mathrm{P}<0.01 \mathrm{com}-$ pared to 2K1C SED (two-way ANOVA followed by the Tukey test). SHAM SED, $\mathrm{n}=10$; SHAM EX, $n=9 ; 2$ K1C SED, $n=9 ; 2$ K1C EX, $n=9$.

Our data corroborate with the results found by Evangelista et al. (2003), who reported the development of cardiac hypertrophy in mice submitted to a swimming protocol during 4 and 6 weeks. The increase in the fiber thickness found in the exercised animal groups SHAM and 2K1C seems to be related to the intensity of training, since the animals submitted to swimming training with $3 \%$ additional charge during 5 weeks displayed an increase in the number of inflammatory cells when compared to sedentary animals with no additional charge (Soares et al., 2011). It is still unknown which mechanisms are directly involved in these responses, but we speculate that there is an interaction between the regulatory pathways of the cardiac hypertrophy after the exercise training, such as AKT-mTOR and IGF-1 (Barry et al., 2008).

We have also evaluated the effect of our physical exercise on the expression of a pathological hypertrophy marker, the BNP (Iso et al., 1997). We observed that its mRNA levels were significantly higher in 2K1C animals compared to SHAM group, and thus corroborating with the data from Mercure et al. (2008), who found a fourfold increase on the BNP expression in mice infused during 19 days with Ang II. To best of our knowledge, there are no studies that associate the response of BNP with exercise in animals with renovascular hypertension. Therefore, our data show that a decrease on the expression levels of this peptide may indicate the effect of the cardiac remodeling evoked by the exercise in 2K1C animals in comparison to the sedentary group (Fig. 6).

Next, we sought to evaluate the expression of some calcium handling proteins that can be modulated by the exercise training, such as: SERCA (Lu et al., 2002), phospholamban (Collins et al., 2005) and NCX1 (Lu et al., 2002).

The SERCA2a plays a central role in the $\mathrm{Ca}^{2+}$ cycle and in excitationcontraction coupling process of the cardiomyocytes, and it is the most expressed isoform in the heart. This calcium pump is composed of a single polypeptide with $110 \mathrm{kDa}$, and it is located in both endoplasmic reticulum and sarcoplasmic reticulum membrane where it transports calcium to the sarcoplasmic reticulum during the diastole (Locatelli et al., 2014).

In this given study, the expression of mRNA and protein levels of SERCA2a increased in the groups submitted to swimming training, which may lead to an improvement in the calcium handling, and subsequently improvement on cardiac function; since it has been shown that decreased protein expression of SERCA2a may alter the cardiac function in SHR (Li et al., 2005). Furthermore, the expression of the SERCA2a protein is significantly reduced in SHR, leading then to abnormal calcium handling ( Li et al., 2005). Therefore, our data are in agreement with the literature. The increase found in the mRNA and protein levels 
of SERCA2a is beneficial to the calcium handling, and supports the beneficial effects of our exercise protocol in the hypertensive heart (Figs. 7 and 8 ).

PLN is a small transmembrane protein located in the sarcoplasmic reticulum (SR) that binds to SERCA2a and inhibits its activity by lowering its apparent affinity for $\mathrm{Ca}^{2+}$ (MacLennan and Kranias, 2003). PLN phosphorylation on Ser16 and Thr17 is physiologically relevant for controlling the activity of SERCA2a (Cerra and Imbrogno, 2012).

Our findings demonstrate that the exercise training is also associated with an increase on the expression of mRNA and protein levels of PLN. Some studies have shown that the exercise training is able to normalize or even to increase the expression and activity of this protein, and also to increase the phosphorylated forms on the residues threonine 17 and serine 16 (Rolim et al., 2007; Medeiros et al., 2008; Wisloff et al., 2001).

The increase on the expression of the mRNA and protein levels of PLN after training may improve the mechanism of calcium uptake, and ventricular function of animals with renovascular hypertension because this may increase the activity of SERCA, which then facilitate the uptake of $\mathrm{Ca}^{2+}$ by the sarcoplasmic reticule (Figs. 9-10). But, in order to firmly state what was previously said, the phosphorylated forms of PLN are needed, as in this study it was not performed such assay; we could not affirm that the swimming training may have increased the activity of SERCA2a.

The (NCX) is a membrane transporter that carries one calcium out of the cell in exchange for three sodium that are send to the cytoplasm, but it may also mediate the flow of both calcium and sodium across the membrane in a bidirectional way (Li et al., 2005). NCX1 is an important regulator of calcium homeostasis in cardiomyocytes, and alterations in its activity may affect the contractility process. It is well known that NCX1 is upregulated at transcriptional level in hearts with hypertrophy and failure (Menick et al., 1996; Hasenfuss et al., 1999).

Some studies have evaluated the effect of aerobic training over the alterations on SERCA2a and NCX1 (Rolim et al., 2007; Sugizaki et al., 2011; Bupha-Intr et al., 2009; Jiao et al., 2012). Corroborating with our result, a study using SHR has demonstrated that the exercise training was able to increase the protein levels of SERCA2a; in addition to any alteration on the NCX1 protein levels (Garciarena et al., 2009). Furthermore, Buttrick et al. (1994) has demonstrated an increase on the mRNA expression levels of SERCA2a in the hearts of renovascular hypertensive rats submitted to 6 weeks of swimming protocol compared to sedentary animals. Despite the great number of studies using different exercise protocols, the majority of these studies have demonstrated normalization or even an increase on the protein levels of SERCA2a in the hearts of rats with or without disorders (Carneiro-Junior et al., 2013; da Costa Rebelo et al., 2012).

An important finding of our study was that the exercise training was able to restore the expression of mRNA levels of NCX1 on the 2K1C EX group. The decrease on the expression of mRNA levels of NCX1 found in the $2 \mathrm{~K} 1 \mathrm{C}$ EX group, in addition to an increase on mRNA and protein levels of SERCA2a, likely represents a compensatory mechanism of $\mathrm{Ca}^{2+}$ removal from the sarcolemma promoted by physical exercise. Thus, given these results, we hypothesize that the exercise training promotes normalization on the levels of NCX1 and SERCA, which prevent the $\mathrm{Ca}^{2+}$ leaking from the cardiomyocytes that ultimately could lead to an imbalance in cell action potential. Therefore, the $\mathrm{Ca}^{2+}$ is retaken by the SR.

Such statement could be criticized since any protein band of NCX1 has not been detected, but only mRNA levels through RT-PCR. Since the overexpression of mRNA and protein levels of NCX1 in cardiac failure and in hypertrophy is well accepted (Hasenfuss et al., 1997; Menick et al., 2007; Cheng et al., 1999); we could say that our exercise protocol has improved the calcium handling in the heart of exercised hypertensive rats, since there was an increase in the expression levels of SERCA2a, and a reduction on NCX1 expression levels in comparison to the sedentary animals.
However, our study has observed huge differences in the mRNA of calcium handling proteins, which were not proportional to the protein levels found. It is known that an increase in mRNA levels is not proportional to the protein levels due to the presence of several genetically driven regulatory mechanisms present in the transcription, RNA processing and translational processes (Maniatis and Reed, 2002; Vogel and Marcotte, 2012). Thus, the differences seen in our study can be at least explained by two reasons: first, the difference in the sensibility between RT-PCR and Western blot techniques; and second, due to the presence of several regulatory mechanisms present in the cell from the genome to the protein level, which ultimately leads to degradation of mRNA that is not translated into protein (Maniatis and Reed, 2002; Vogel and Marcotte, 2012).

Indeed, the literature is still controversial regarding the effects of the exercise training on the expression of proteins that are involved on the calcium handling process in the cardiac tissue. The exercise training can delay the cardiac dysfunction, which can be attributed, at least in part, to the cardiac remodeling, and to an upregulated balance of cardiac proteins that are involved in sarcoplasmic reticulum calcium release and reuptake.

Taken altogether, our exercise protocol has beneficial effects on the expression of SERCA2a, PLN, and NCX1, which are key proteins for the proper regulation of the calcium handling. Furthermore, our data show that the exercise protocol used in this study was not able to fully reverse the pathological hypertrophy caused by hypertension, but it was able to reduce the levels of blood pressure and BNP; since it seems our exercise protocol is in a transitional phase regarding cardiac remodeling. Therefore, further investigations are necessary in order to identify the possible mechanisms involved in cardiac remodeling and modulation of the calcium handling proteins in hearts of rats with renovascular hypertension and to analyze the effectiveness of the exercise training as a therapeutic approach.

\section{Conclusion}

Our results suggest that aerobic training: may promote eccentric cardiac hypertrophy in normotensive rats; modulates the expression of some calcium handling proteins in the heart of renovascular hypertensive rats, such as: SERCA2a, PLN and NCXI; and reduces the expression of BNP, which is a pathological hypertrophy marker. Furthermore, we observed that the duration of our exercise training did not fully reverse the concentric hypertrophy caused by renovascular hypertension. Therefore, we have shown important findings that contribute to the better understanding of the cardiac alterations that occur during the onset of hypertension.

\section{Competing interests}

None declared.

\section{Acknowledgments}

The research was supported by Fundação de Amparo à Pesquisa do Estado de Minas Gerais (FAPEMIG), grants APQ-02112-10 and APQ 00793-13; RedeToxifar, Conselho Nacional de Desenvolvimento Científico e Tecnológico (CNPQ); Instituto Nacional de Ciência e Tecnologia (INCT); and Programa de Apoio a Núcleos de Excelência. The coauthor de Assis. L.V.M. is a Fellow of São Paulo Research Foundation (FAPESP-Process 2013/24337-4). All the authors are thankful to Pablo Henrique Oliveira e Silva for extensively revising this manuscript.

\section{References}

Arjamaa O. Physiology of natriuretic peptides: the volume overload hypothesis revisited. World J Cardiol 2014;6(1):4-7.

Barry SP, Davidson SM, Townsend PA. Molecular regulation of cardiac hypertrophy. Int J Biochem Cell Biol 2008;40(10):2023-39. 
Benigni A, Cassis P, Remuzzi G. Angiotensin II revisited: new roles in inflammation, immunology and aging. EMBO Mol Med 2010;2(7):247-57.

Briet M, Schiffrin EL. Aldosterone: effects on the kidney and cardiovascular system. Nat Rev Nephrol 2010;6(5):261-73.

Bupha-Intr T, Laosiripisan J, Wattanapermpool J. Moderate intensity of regular exercise improves cardiac SR Ca2 + uptake activity in ovariectomized rats. J Appl Physiol (1985) 2009;107(4):1105-12.

Buttrick PM, Kaplan M, Leinwand LA, Scheuer J. Alterations in gene expression in the rat heart after chronic pathological and physiological loads. J Mol Cell Cardiol 1994; 26(1):61-7.

Carneiro-Junior MA, Quintão-Júnior JF, Drummond LR, Lavorato VN, Drummond FR, da Cunha DN, et al. The benefits of endurance training in cardiomyocyte function in hypertensive rats are reversed within four weeks of detraining. J Mol Cell Cardiol 2013; 57:119-28.

Cerra MC, Imbrogno S. Phospholamban and cardiac function: a comparative perspective in vertebrates. Acta Physiol (Oxf) 2012;205(1):9-25.

Cheng G, Hagen TP, Dawson ML, Barnes KV, Menick DR. The role of GATA, CArG, E-box, and a novel element in the regulation of cardiac expression of the $\mathrm{Na}^{+}-\mathrm{Ca}^{2+}$ exchanger gene. J Biol Chem 1999;274(18):12819-26.

Collins HL, Loka AM, Dicarlo SE. Daily exercise-induced cardioprotection is associated with changes in calcium regulatory proteins in hypertensive rats. Am J Physiol Heart Circ Physiol 2005;288(2):H532-40.

da Costa Rebelo RM, Schreckenberg R, Schlüter KD. Adverse cardiac remodelling in spontaneously hypertensive rats: acceleration by high aerobic exercise intensity. J Physiol 2012;590(Pt 21):5389-400.

de Waard MC, van der Velden J, Bito V, Ozdemir S, Biesmans L, Boontje NM, et al. Early exercise training normalizes myofilament function and attenuates left ventricular pump dysfunction in mice with a large myocardial infarction. Circ Res 2007; 13(100(7)):1079-88.

Duncan JJ, Farr JE, Upton SJ, Hagan RD, Oglesby ME, Blair SN. The effects of aerobic exercise on plasma catecholamines and blood pressure in patients with mild essential hypertension. JAMA 1985;254(18):2609-13.

Edwards EW, DiPette DJ, Townsend RR, Cohen DL. Top 10 landmark studies in hypertension. J Am Soc Hypertens 2014;8(6):437-47.

Egger M, Domenighetti AA. Adaptive and maladaptive remodeling of cardiomyocyte excitation-contraction coupling by angiotensin II. Trends Cardiovasc Med 2010; 20(3):78-85.

Evangelista FS, Brum PC, Krieger JE. Duration-controlled swimming exercise training induces cardiac hypertrophy in mice. Braz J Med Biol Res 2003;36(12):1751-9.

Flesch M, Schwinger RH, Schnabel P, Schiffer F, van Gelder I, Bavendiek U, et al. Sarcoplasmic reticulum $\mathrm{Ca} 2+$ ATPase and phospholamban mRNA and protein levels in endstage heart failure due to ischemic or dilated cardiomyopathy. J Mol Med (Berl) 1996;74(6):321-32.

Garciarena CD, Pinilla OA, Nolly MB, Laguens RP, Escudero EM, Cingolani HE, et al. Endurance training in the spontaneously hypertensive rat: conversion of pathological into physiological cardiac hypertrophy. Hypertension 2009;53(4):708-14.

Hasenfuss G, Meyer M, Schillinger W, Preuss M, Pieske B, Just H. Calcium handling proteins in the failing human heart. Basic Res Cardiol 1997;92(Suppl. 1):87-93.

Hasenfuss G, Schillinger W, Lehnart SE, Preuss M, Pieske B, Maier LS, et al. Relationship between $\mathrm{Na}^{+}-\mathrm{Ca}^{2+}$ exchanger protein levels and diastolic function of failing human myocardium. Circulation 1999;99(5):641-8.

Hirata Y, Matsumoto A, Aoyagi T, Yamaoki K, Komuro I, Suzuki T, et al. Measurement of plasma brain natriuretic peptide level as a guide for cardiac overload. Cardiovasc Res 2001:51(3):585-91.

Iso T, Arai M, Wada A, Kogure K, Suzuki T, Nagai R. Humoral factor(s) produced by pressure overload enhance cardiac hypertrophy and natriuretic peptide expression. Am J Physiol 1997;273(1 Pt 2):H113-8.

Janicki JS, Brower GL. The role of myocardial fibrillar collagen in ventricular remodeling and function. J Card Fail 2002;8(6 Suppl):S319-25.

Jiao Q, Takeshima H, Ishikawa Y, Minamisawa S. Sarcalumenin plays a critical role in agerelated cardiac dysfunction due to decreases in SERCA2a expression and activity. Cell Calcium 2012;51(1):31-9.

Kemi OJ, Høydal MA, Haram PM, Garnier A, Fortin D, Ventura-Clapier R, et al. Exercise training restores aerobic capacity and energy transfer systems in heart failure treated with losartan. Cardiovasc Res 2007;76(1):91-9.

Kim HN, Januzzi Jr JL. Natriuretic peptide testing in heart failure. Circulation 2011; 123(18):2015-9.

Kohlmann Jr O, Guimarães AC, Carvalho MHC, Chaves Jr HC, Machado CA, Praxedes JN et al. III Consenso Brasileiro de Hipertensão Arterial. Arq Bras Endocrinol Metabol 1999;43:257-86.

Kwak HB, Song W, Lawler JM. Exercise training attenuates age-induced elevation in Bax/ Bcl-2 ratio, apoptosis, and remodeling in the rat heart. FASEB J 2006;20(6):791-3.

Kwak HB, Kim JH, Joshi K, Yeh A, Martinez DA, Lawler JM. Exercise training reduces fibrosis and matrix metalloproteinase dysregulation in the aging rat heart. FASEB J 2011; 25(3):1106-17.

Li SY, Golden KL, Jiang Y, Wang GJ, Privratsky JR, Zhang X. Inhibition of sarco(endo) plasmic reticulum $\mathrm{Ca} 2+-$ ATPase differentially regulates contractile function in cardiomyocytes from normotensive and spontaneously hypertensive rats: role of $\mathrm{Ca} 2+$ regulatory proteins. Cell Biochem Biophys 2005;42(1):1-12.
Locatelli J, de Assis LV, Isoldi MC. Calcium handling proteins: structure, function, and modulation by exercise. Heart Fail Rev 2014;19(2):207-25.

Loud AV, Anversa P, Giacomelli F, Wiener J. Absolute morphometric study of myocardial hypertrophy in experimental hypertension. I. Determination of myocyte size. Lab Invest 1978;38(5):586-96.

Lu L, Mei DF, Gu AG, Wang S, Lentzner B, Gutstein DE, et al. Exercise training normalizes altered calcium-handling proteins during development of heart failure. J Appl Physio (1985) 2002;92(4):1524-30.

MacLennan DH, Kranias EG. Phospholamban: a crucial regulator of cardiac contractility. Nat Rev Mol Cell Biol 2003 Jull;4(7):566-77.

Maniatis T, Reed R. An extensive network of coupling among gene expression machines. Nature 2002;416(6880):499-506.

Medeiros A, Rolim NP, Oliveira RS, Rosa KT, Mattos KC, Casarini DE, et al. Exercise training delays cardiac dysfunction and prevents calcium handling abnormalities in sympathetic hyperactivity-induced heart failure mice. J Appl Physiol (1985) 2008;104(1): 103-9.

Menick DR, et al. The exchanger and cardiac hypertrophy. Ann N Y Acad Sci 1996;779: 489-501.

Menick DR, Renaud L, Buchholz A, Müller JG, Zhou H, Kappler CS, et al. Regulation of Ncx1 gene expression in the normal and hypertrophic heart. Ann N Y Acad Sci 2007;1099: 195-203.

Mercure C, Yogi A, Callera GE, Aranha AB, Bader M, Ferreira AJ, et al. Angiotensin(1-7) blunts hypertensive cardiac remodeling by a direct effect on the heart. Circ Res 2008;103(11):1319-26.

Molmen-Hansen HE, Stolen T, Tjonna AE, Aamot IL, Ekeberg IS, Tyldum GA, et al. Aerobic interval training reduces blood pressure and improves myocardial function in hypertensive patients. Eur J Prev Cardiol 2012;19(2):151-60.

Nakatsu T, Shinohata R, Mashima K, Yuki Y, Nishitani A, Toyonaga S, et al. Use of plasma Btype natriuretic peptide level to identify asymptomatic hypertensive patients with abnormal diurnal blood pressure variation profiles: nondippers, extreme dippers, and risers. Hypertens Res 2007;30(7):651-8.

Ogawa Y, Nakao K, Mukoyama M, Hosoda K, Shirakami G, Arai H, et al. Natriuretic peptides as cardiac hormones in normotensive and spontaneously hypertensive rats. The ventricle is a major site of synthesis and secretion of brain natriuretic peptide. Circ Res 1991;69(2):491-500.

Padmalayam I. Targeting mitochondrial oxidative stress through lipoic acid synthase: a novel strategy to manage diabetic cardiovascular disease. Cardiovasc Hematol Agents Med Chem 2012;10(3):223-33.

Reckelhoff JF, Zhang H, Srivastava K. Gender differences in development of hypertension in spontaneously hypertensive rats: role of the renin-angiotensin system. Hypertension 2000;35(1 Pt 2):480-3.

Rodrigues MC, Campagnole-Santos MJ, Machado RP, Silva ME, Rocha JL, Ferreira PM, et al Evidence for a role of AT(2) receptors at the CVLM in the cardiovascular changes induced by low-intensity physical activity in renovascular hypertensive rats. Peptides 2007;28(7):1375-82.

Rolim NP, Medeiros A, Rosa KT, Mattos KC, Irigoyen MC, Krieger EM, Krieger JE, et al. Exercise training improves the net balance of cardiac $\mathrm{Ca} 2+$ handling protein expression in heart failure. Physiol Genomics 2007;29(3):246-52.

Semlitsch T, Jeitler K, Hemkens LG, Horvath K, Nagele E, Schuermann C, Pignitter N, et al Increasing physical activity for the treatment of hypertension: a systematic review and meta-analysis. Sports Med 2013;43(10):1009-23.

Soares ER, Lima WG, Machado RP, Carneiro CM, Silva ME, Rodrigues MC, et al. Cardiac and renal effects induced by different exercise workloads in renovascular hypertensive rats. Braz J Med Biol Res 2011;44(6):573-82.

Sugizaki MM, Leopoldo AP, Conde SJ, Campos DS, Damato R, Leopoldo AS, et al. Exercício e restrição alimentar aumentam o RNAm de proteínas do trânsito de Ca2 + miocárdico em ratos. Arq Bras Cardiol 2011;97:46-52.

Suzuki M, Hamada M, Yamamoto K, Kazatani Y, Hiwada K. Brain natriuretic peptide as a risk marker for incident hypertensive cardiovascular events. Hypertens Res 2002; 25(5):669-76

Takahashi N, Smithies O. Human genetics, animal models and computer simulations for studying hypertension. Trends Genet 2004;20(3):136-45.

Thomas DP, Cotter TA, Li X, McCormick RJ, Gosselin LE. Exercise training attenuates agingassociated increases in collagen and collagen crosslinking of the left but not the right ventricle in the rat. Eur J Appl Physiol 2001;85(1-2):164-9.

Vogel C, Marcotte EM. Insights into the regulation of protein abundance from proteomic and transcriptomic analyses. Nat Rev Genet 2012;13(4):227-32.

Wakatsuki T, Schlessinger J, Elson EL. The biochemical response of the heart to hypertension and exercise. Trends Biochem Sci 2004;29(11):609-17.

Weber M, Hamm C. Role of B-type natriuretic peptide (BNP) and NT-proBNP in clinica routine. Heart 2006:92(6):843-9.

Weber KT, Janicki JS, Pick R, Abrahams C, Shroff SG, Bashey RI, et al. Collagen in the hypertrophied, pressure-overloaded myocardium. Circulation 1987;75(1 Pt 2):I40-7.

Weber KT, Brilla CG, Janicki JS. Myocardial remodeling and pathologic hypertrophy. Hosp Pract (Off Ed) 1991;26(4):73-80.

Wisloff U, Loennechen JP, Falck G, Beisvag V, Currie S, Smith G, et al. Increased contractility and calcium sensitivity in cardiac myocytes isolated from endurance trained rats. Cardiovasc Res 2001;50(3):495-508. 